\title{
Qualification of Alternative Jet Fuels
}

\author{
Mark A. Rumizen * \\ Federal Aviation Administration, Aircraft Certification, Senior Technical Experts Program, Burlington, MA, United States
}

Historically, the commercial aviation industry has relied on a very limited number of wellproven, conventional fuels for certification and operation of aircraft and engines. The vast majority of today's engines and aircraft were designed and certified to operate on one of two basic fuels; kerosene-based fuel for turbine powered aircraft and leaded AVGAS for spark ignition reciprocating engine powered aircraft. These fuels are produced and handled as bulk commodities with multiple producers sending fuel through the distribution system to airports and aircraft. They are defined and controlled by industry consensus-based fuel specifications that, along with the oversight of the ASTM International aviation fuel industry committee, accommodate the need to move the fuel as a commodity. It was therefore expedient to build upon this framework when introducing drop-in jet fuel produced from non-petroleum feed stocks into the supply chain. The process developed by the aviation fuel community utilizes the ASTM International Aviation Fuel Subcommittee (Subcommittee J) to coordinate the evaluation of data and the

OPEN ACCESS

Edited by: Zia Haq,

United States Department of Energy (DOE), United States

Reviewed by: Ravi Fernandes, Physikalisch-Technische Bundesanstalt, Germany

Robert L. McCormick,

National Renewable Energy Laboratory (DOE), United States

*Correspondence:

Mark A. Rumizen mark.rumizen@faa.gov

Specialty section:

This article was submitted to Bioenergy and Biofuels,

a section of the journal

Frontiers in Energy Research

Received: 18 August 2021 Accepted: 05 October 2021 Published: 02 November 2021

Citation:

Rumizen MA (2021) Qualification of Alternative Jet Fuels.

Front. Energy Res. 9:760713. doi: 10.3389/fenrg.2021.760713 establishment of specification criteria for new non-petroleum (alternative) drop-in jet fuels. Subcommittee $J$ has issued two standards to facilitate this process; ASTM D4054 - "Standard Practice for Qualification and Approval of New Aviation Turbine Fuels and Fuel Additives", and ASTM D7566- "Standard Specification for Aviation Turbine Fuel Containing Synthesized Hydrocarbons". This paper will describe how the aviation fuel community utilizes the ASTM International consensus-based process to evaluate new candidate non-petroleum jet fuels to determine if these new fuels are essentially identical to petroleum derived jet fuel, and, if they are, to issue specifications to control the quality and performance of these fuels.

Keywords: jet fuel, alternative, sustainable, aviation, qualification, certification, sustainable aviation fuels

\section{INTRODUCTION}

Airworthiness standards are regulations established by the national aviation authorities for oversight of the design and operation of aircraft. The airworthiness standards applicable to the oversight of aviation fuel were a key consideration when developing the industry qualification process for alternative jet fuels. These standards compelled the aviation fuel community to focus on drop-in alternative jet fuels as the most expeditious path to supplanting petroleum-derived jet fuels.

\subsection{Aviation Fuel Regulatory Overview}

The regulations established by the United States' Federal Aviation Administration (FAA) for oversight of the design and operation of aircraft are called "airworthiness standards". The FAA's airworthiness standards applicable to the design of aircraft and engines consider fuel as an operating limitation, as opposed to a physical part of the product. As an operating limitation, the aviation fuels permitted for use are merely identified by the engine and aircraft manufacturer (OEM), rather than 
TABLE 1 | D4054 Tier 1 properties.



produced under the OEM's quality control system. This facilitates the handling of aviation fuel as a commodity in a fungible supply system where any fuel producer can supply fuel to any aircraft as long as that fuel meets the requirements specified by the OEM (typically an industry fuel specification such as ASTM). In the supply chain, aviation fuel travels in close proximity to other types of fuel where it is exposed to possible mixing and contamination with other non-aviation fuels such as diesel and gasoline. Other sources of contamination exist at all points in the supply chain, requiring periodic spot checking of fuel quality relative to the specification requirements. Also, jet fuel is shipped in very large batches that can be combined with other jet fuel batches from other sources while in transit, thereby losing initial batch identity and associated fuel property data. Because jet fuel is traded as a commodity, ownership of batches of fuel can change hands several times throughout its journey to the airport.

In recognition of this distribution system and the possible changing nature of liquid fuels, FAA regulations are targeted at the end point of the supply chain; the aircraft. The regulations require the aircraft and engine manufacturer to specify the fuel (or fuels) that are permitted for use on the aircraft, and the regulations then require the aircraft operator (or airline) to only use those fuels listed by the manufacturer. How those fuels are produced, transported, or otherwise handled upstream of the wing of the aircraft is beyond the reach of FAA (and other national aviation authorities) regulations.

\subsection{Conventional Jet Fuel}

The primary aviation fuel specifications used globally to ensure a jet fuel supply with consistent properties and performance include ASTM International D1655 (ASTM International Standard D1655, 1942), UK MOD Defence Standard 91-091 (Defence Standard 91-091, 1138), and the U.S. military MILDTL-83133 (Mil-Dtl-83133, 2430), and MIL-DTL-5624 (MilDtl-5624, 1873). Conventional jet fuel defined in these and other specifications is produced from petroleum and was 
originally derived from illuminating kerosene. The jet fuel specifications introduced fuel property criteria to accommodate the operational demands of aviation. As aircraft and engine technology advanced and more demands were placed on the performance of jet fuel, additional criteria were introduced to more tightly control the performance and properties of the fuel. Key criteria necessary to support aircraft operations at the cold temperatures experienced at high altitudes include a $-40^{\circ} \mathrm{C}$ freezing point and a viscosity limit of $8 \mathrm{~mm}^{2} / \mathrm{s}$ at $-20^{\circ} \mathrm{C}$. A thermal stability test method was developed and criteria added to the specification to prevent fuel system deposit formation at the high operating temperatures experienced in gas turbine engine fuel systems. The complete list of criteria can be found in Table 1 of ASTM International D1655 (ASTM International Standard D1655, 1942).

Contemporary jet fuel derived from petroleum and produced in accordance with ASTM International D1655 (ASTM International Standard D1655, 1942) is comprised of a mix of hydrocarbons that typically range from eight to fifteen carbon atoms. These hydrocarbons are comprised of approximately $60 \%$ paraffins, $25 \%$ cycloparaffins, and $15 \%$ aromatics, but note that these concentrations do vary somewhat with each batch of jet fuel. The properties and composition of conventional jet fuel form the basis for comparison when evaluating alternative jet fuels.

\subsection{Drop-In Alternative Jet Fuels}

Prompted by supply security and environmental concerns with petroleum, the aviation fuel community formed the Commercial Aviation Alternative Fuel Initiative (CAAFI ${ }^{\circledR}$ ) coalition in 2006 to promote the development and deployment of alternative aviation fuels. One of the key initial decisions of the organizers was to limit the scope of their effort to drop-in jet fuels. These fuels are defined as have essentially identical properties and composition relative to the existing petroleum-derived jet fuel that is currently used by the today's fleet of commercial and military aircraft. As essentially identical jet fuels, the alternative jet fuels would then be compatible with the existing fleet of aircraft and jet fuel distribution infrastructure. Additionally, because these fuels would be considered the same Jet A/A-1 fuel already approved for use on virtually all commercial aircraft, no special regulatory approval would be required to operate with the fuels. Consequently, CAAFI looked to ASTM International to develop standards to support the evaluation and issuance of specifications for drop-in alternative jet fuels to facilitate the entry into service of these fuels.

ASTM International subcommittee D01. J oversees aviation fuel specifications. The subcommittee is comprised of stakeholders from all elements of the production/distribution/ operational supply chain, such as petroleum refining, pipelines, ground handling equipment (such as filtration systems), test instruments, engine/aircraft manufacturers, airlines, military, and government agencies such as the Federal Aviation Administration (FAA). The alternative jet fuel qualification process described below initially relies on the technical review of the engine and aircraft manufactures to determine if the proposed fuel is fit for purpose for aviation. After that hurdle is passed, then the new proposed specification along with supporting data is balloted to the entire ASTM International subcommittee D02. J to assure compatibility with the remainder of the supply chain.

\section{OVERVIEW OF THE QUALIFICATION PROCESS}

ASTM D4054, "Standard Practice for Evaluation of New Aviation Turbine Fuels and Fuel Additives" (ASTM International Standard D4054, 1942), describes the test and evaluation program created by the members of ASTM's aviation fuel subcommittee to compare the properties and performance of alternative jet fuels to those of petroleum-derived jet fuels. The very rigorous and comprehensive test program defined in D4054 is necessary due to the critical role that jet fuel plays in the safe operation of an aircraft. If, after reviewing the data, the subcommittee members agree that the candidate alternative jet fuel is essentially identical to petroleum-derived jet fuel, then specification criteria for the new alternative jet fuel is incorporated into the drop-in fuel specification; D7566, "Standard Specification for Aviation Turbine Fuel Containing Synthesized Hydrocarbons."

ASTM D4054 is intended to be a guideline, not a prescriptive document. As such, it provides a candidate alternative jet fuel producer with information regarding testing and property targets necessary to evaluate the proposed fuel. D4054 is an iterative process, which requires the candidate fuel developer to test samples of fuel to measure properties, composition, and performance and to then periodically review those results with key aviation fuel industry stakeholders such as engine and aircraft manufacturers. These reviews typically result in questions and comments that in turn might drive the need for additional testing. The testing is divided into four tiers as described in the following sections.

\subsection{Tier 1: Basic Specification Properties}

The jet fuel specifications described above list fuel property criteria for jet fuel produced from petroleum, shale oil or tar sands, but may also include additional criteria for jet fuel produced from alternative raw materials. The criteria listed in these specifications are not considered sufficient for determining the suitability of jet fuels made from all other raw materials, but they do represent the minimum required performance of a jet fuel. The typical specification properties are summarized in Table 1. The Tier 1 testing requirements are relatively inexpensive (approximately \$5,000) (ASTM, 2018) and require only small quantities of fuel (less than 10 gallons).

\subsection{Tier 2: Fit-For-Purpose Properties}

The specification properties tested in Tier 1 represent a subset of the jet fuel properties that must be controlled to ensure safe and proper aircraft and engine operation. There are many other properties that are inherent in petroleum-derived jet fuel and therefore are not listed in the jet fuel specifications. These properties, which are called Fit-For-Purpose (FFP) properties, 
do not need to be routinely measured because they are relatively consistent for jet fuels produced from petroleum using conventional, well-understood refining processes. However, it is necessary to measure FFP properties for fuels produced from other materials, such as renewable feedstocks, to determine if the alternative jet fuel is acceptable for use on current or future technology aircraft and engines. These tests cost up to $\$ 50,000$ (ASTM, 2018) and may require up to 100 gallons of fuel (ASTM, 2018). An overview of the FFP properties is provided below.

\subsubsection{Chemical Composition}

The concentration of hydrocarbons and trace materials are measured using advanced analytical chemistry methods such as two-dimensional gas chromatography. This test method provides the concentration of each hydrocarbon compound class (isoparaffin, normal paraffin, cycloparaffin, and aromatic) along with the carbon number distribution within each of these classes. The results are then compared to the typical composition petroleum-derived jet fuels. Significant differences to this compositional footprint might drive the need for additional testing. High concentrations of materials that are normally at trace levels in jet fuel (ASTM International Standard D4054, 1942), such as metals or oxygenates, may also be cause for further investigation.

\subsubsection{Bulk Physical and Performance Properties}

Predictable variation of fuel properties over the operating range of the aircraft and engine is necessary for safe and proper operation of the fuel, combustion, and hydraulic systems. The temperature dependencies of fuel properties such as density, surface tension, viscosity, and permittivity are compared with those of conventional jet fuel. These properties have been found to be linear functions of temperature for pure hydrocarbon fuels, except for isentropic bulk modulus which is influenced by the speed of sound (Heyne, 2021). These properties will be consistent with typical jet fuels if the hydrocarbon composition is similar to conventional jet fuel.

\subsubsection{Electrical Properties}

Dielectric constant (or permittivity) and conductivity are the electrical properties evaluated under D4054. The dielectric constant of a fuel is the ratio of the electrical capacitance of a fuel to the electrical capacitance of air. This property can influence the accuracy of aircraft fuel quantity indicating systems that rely on fuel tank capacitance probes to measure the fuel level. Dielectric constant is measured relative to density because many of these systems compensate for fuel density (Mil-Hdbk-510A, 2017). The other property, electrical conductivity, is related jet fuel's ability to readily dissipate static electricity which has built up during transportation of the fuel. This is an important safety concern because electrostatic sparks in the proximity of jet fuel can cause explosive response and associated fire. The response of a fuel's electrical conductivity to the addition of Static Dissipator Additive (SDA) is evaluated to ensure the alternative jet fuel responds in the same manner as conventional jet fuel.

\subsubsection{Ground Handling Properties and Safety}

The fuel's compatibility with existing ground filtration systems is evaluated along with its storage stability, toxicity and flammability. These evaluations are conducted to ensure that the alternative jet fuel can be handled in the same manner as conventional jet fuel.

\subsubsection{Compatibility With Approved Additives}

The solubility of all currently approved jet fuel additives is evaluated over the operating temperature range of the aircraft to ensure that there are no limitations on use of the additives.

\subsubsection{Preliminary Compatibility With Engine and Airframe Seals}

Three types of elastomeric seals are soak-tested with the candidate fuel to determine if they respond differently than when soaked in conventional jet fuel. The results of this testing are used to determine if more extensive material compatibility testing is required in Tier 3 .

\subsection{Tier 3: Engine/Aircraft Systems Rig and Component Testing}

The scope of the Tier 3 and Tier 4 testing is based on the evaluation of the Tier 1 and 2 data. The ASTM committee relies on the expertise of the aircraft and engine OEMs to determine this scope due to complexity and advanced technologies of modern gas turbine engines and aircraft, and because Tier 3 and 4 tests typically require the use of OEM specialized equipment, rigs, and facilities. The amount of fuel required for these tests can vary widely from 250 to 15,000 gallons depending on the types of tests required and the cost can be as high as $\$ 1.5 \mathrm{M}$. An overview of typical Tier 3 tests is provided below:

\subsubsection{Compatibility With Engine and Airframe Seals, Coatings and Metallics}

A wide range of materials that represents the current aircraft fleet are soak-tested in the candidate fuel to determine if they respond in the same manner as with conventional Jet A. The list of materials to be tested includes 37 non-metallics and 31 metals (ASTM International Standard D4054, 1942). The scope of this testing will depend on the compositional similarity to conventional Jet A fuel and the results of the preliminary materials compatibility testing.

\subsubsection{Turbine Hot Section Testing}

Hot section parts such as turbine blades or nozzles are evaluated for corrosive attack by exposure to a high temperature flame from combustion of the candidate alternative fuel on a burner rig.

\subsubsection{Fuel System Testing}

This includes such tests as fuel component acceptance testing, fuel nozzle (atomizer) spray testing, and atomizer plugging under cold operating conditions. 


\subsubsection{Combustor Rig Testing}

This testing evaluates combustor operability, performance, durability, or emissions when operating with the alternative jet fuel. A full-scale combustor is installed in a test chamber where pressures and temperatures across the engine operating envelope can be simulated. Typical tests include cold starting, lean blowout at high altitude/low power conditions, turbine inlet temperature distribution, and gaseous and smoke emissions.

\subsubsection{Auxiliary Power Unit Tests}

Ignition tests on full-scale APUs are conducted at cold and altitude conditions in addition to combustor rig tests described above.

\subsubsection{Aircraft Fuel System Rig Testing}

Tests that have been conducted include ice accretion tests on aircraft fuel system rigs and fuel level measurement accuracy.

\subsection{Tier 4: Full-Scale Engine Testing or Aircraft Flight Testing}

Full-scale engine tests may be required to evaluate performance, operability, emissions or long-term durability when operating with the candidate alternative jet fuel. Engine tests may require up to 200,000 gallons of fuel and may cost up to $\$ 1 \mathrm{M}$ (ASTM, 2018). Emissions testing can typically be accomplished concurrently with other engine tests. Aircraft flight tests are typically not required, as it is difficult to cover the critical areas of the flight envelope during a flight test, but in some cases they may be necessary. Aircraft flight testing is typically focused on performance and operability characteristics. Fuel consumption is measured, in-flight restarts and throttle transients are accomplished. The testing may also include aircraft fuel system dedicated tests such as fuel boost pump operation and fuel transfer between fuel tanks.

\section{PROCESS IMPROVEMENTS TO THE QUALIFICATION PROCESS}

\subsection{Pre-Screening of Candidate Alternative Jet Fuels}

The D4054 process is a resource intensive process for both the prospective alternative jet fuel producer and the reviewing community. It typically requires a demo-scale production capability to produce the 50 to 100 gallons of fuel required for evaluation and testing, and results in reports that contain up to several hundred pages. Research conducted under the U.S. National Jet Fuel Combustion Program (NJFCP) (Colket et al., 2017) and the European JETSCREEN program (Rauch, 2020) provided the analytical tools to enable very small volumes of candidate alternative jet fuel to be analyzed to determine viability for use in aircraft. While not part of the D4054 process, these PreScreening analytical tools and methods that are now available from CAAFI (CAAFI). They enable developers of alternative jet fuel to refine their processes using laboratory-scale equipment and very small fuel volumes to produce products that are more likely to successfully complete the above described qualification process before investing in process scale-up. Pre-Screening utilizes advanced analytical methods such as two-dimensional gas chromatography, mid-infrared absorption, and nuclear magnetic resonance, along with testing of physical properties such as viscosity, distillation curve, mass density, flash point, derived cetane number (DCN), and surface tension.

\subsection{ASTM D4054 Fast Track Process}

The ASTM D4054 process described above includes extensive test and evaluation requirements and therefore requires a significant level of resources to accomplish. This was necessary to ensure the fit for purpose of the candidate alternative jet fuel for use on aircraft and engines. The ASTM International subcommittee $\mathrm{J}$, in close cooperation with the engine and aircraft manufactures, reviewed past data accumulated from testing and evaluation of the approved alternative jet fuels. It was agreed that reduced testing requirements could be made available to producers of new alternative jet fuel blending components that fell within compositional and performance range of a typical conventional jet fuel. These reduced testing requirements were incorporated as Annex A4 of D4054 in September 2020 and called the Fast Track process. The annex specifies target values as a guideline and starting point for the evaluation of candidate alternative jet fuels for entry into the fast track process. The target values were established to characterize a nominal jet fuel with mid-range properties and with a typical hydrocarbon composition. For example, maximum and minimum temperature limitations are specified for distillation points across the entire distillation range, and specially developed gas chromatographic methods are specified for detailed identification of hydrocarbon molecular classes and distribution and polar molecules. The Fast Track annex imposes a 10\% maximum blending limit as a tradeoff with the reduced testing requirements.

\section{THE PRODUCT OF THE EVALUATION PROCESS; A NEW SPECIFICATION ANNEX}

\subsection{ASTM D7566: The Drop-In Fuel Specification}

ASTM D7566- "Standard Specification for Aviation Turbine Fuel Containing Synthesized Hydrocarbons" (ASTM International Standard D7566, 1942) is a stand-alone specification that is separate and distinct from the petroleumderived (or conventional) jet fuel specification D1655. The decision to issue a separate specification was driven by the need to incorporate more stringent criteria for these new fuels that were lacking any demonstrable service experience, and by the concern from petroleum producers of this more stringent criteria being applied to their mature, well understood fuels. D7566 also includes a provision to allow "re-designation" of D7566 jet fuel 
batches to D1655 fuel to enable these new fuels to fit within the existing jet fuel supply and operational infrastructure which based on the D1655 conventional jet fuel specification. This resulted in a stand-alone specification that provided more stringent criteria for production, yet enabled seamless integration into the existing infrastructure including meeting existing certification requirements.

The initial conversion processes considered for incorporation into D7566 produced hydrocarbon products that were compositional subsets of a typical conventional jet fuel. For example, both the Fischer-Tropsch process (see A1: FischerTropsch Hydroprocessed Synthesized Paraffinic Kerosene below) and the HEFA process (see A2: Synthesized Paraffinic Kerosene From Hydroprocessed Esters and Fatty Acids below) result in a pure paraffinic fuel, lacking the $8-20 \%$ aromatic concentration found in conventional jet fuel. Therefore, blending with conventional jet fuel was necessary to create a jet fuel composition with an aromatics concentration and density that was within the experience base of conventional jet fuel. For those alternative jet fuels that had a composition that was consistent with conventional jet fuel, such as Annex A4 Fischer-Tropsch Synthesized Paraffinic Kerosene with Aromatics (FT-SPK/A) (see A4: Synthesized Kerosine With Aromatics Derived by Alkylation of Light Aromatics From Non-petroleum Sources below) and Annex A6 Catalytic Hydrothermolysis Jet (CHJ) (see A6: Synthesized Kerosene From Hydrothermal Conversion of Fatty Acid Esters and Fatty Acids below), a 50\% maximum blending limit was imposed as a conservative approach to entry into service. To accommodate the need for blending, a two-step approach was implemented where first the alternative jet fuel must meet criteria specified in an annex unique to that fuel, then after blending with conventional jet to below a prescribed limit, the finished jet fuel is again tested to criteria specified in the main body of the specification.

The property tables in each annex also are a key, unique characteristic of D7566. Each annex contains two of these tables, the first of which specifies primarily physical properties such as density, freezing point, distillation and thermal stability, which must be measured for each batch of fuel. The second table specifies compositional criteria intended to support management of change events such as the start of production, significant changes to the process, or as necessary to support continued production of a consistent, high quality product. However, currently all of the annexes except Annex A1 require measurement of these properties for each batch of alternative fuel blend component. As more experience is gained with fuel produced to the other annexes, the testing requirements for the second tables will be moved from batch frequency to a management of change frequency (ASTM International Standard D7566, 1942).

\subsection{Overview of the D7566 Annexes}

There are currently seven annexes in D7566 that have been periodically added since the initial issuance of the specification in 2009. The issuance of each annex followed a rigorous testing program conducted in accordance with D4054 as described above and balloting to the ASTM membership. Each annex includes a description of the conversion process, feedstock, and composition of the resulting alternative fuel along with property requirements that the alternative fuel must meet.

\subsubsection{A1: Fischer-Tropsch Hydroprocessed Synthesized Paraffinic Kerosene}

The FT-SPK process specifies a feed stock of carbon monoxide and hydrogen synthesis gas. This synthesis gas is produced from the gasification of coal or biomass, reforming of natural gas, or other means of producing hydrogen and carbon. The synthesis gas is converted to a liquid hydrocarbon product in the FT reactor that is comprised primarily of isoparaffins. Typical refinery processing techniques such as hydroprocessing or isomerization are then used to produce a jet fuel blending component primarily composed iso-paraffins distributed across the jet fuel carbon number range. The Annex allows blending up to $50 \%$ by volume FT SPK with Jet A, subject to property limitations such as density and aromatics concentration on the final blended jet fuel. Blending is required to add the normal paraffins, cycloparaffins and aromatics that are absent from the FT-SPK.

\subsubsection{A2: Synthesized Paraffinic Kerosene From Hydroprocessed Esters and Fatty Acids}

The annex defines the feed stocks as mono-, di-, and tri-glycerides, free fatty acids and fatty acid esters. Typical tri-glyceride feed stocks are soybean, algae, other plant oils, or tallow. The HEFA conversion process consists of a catalytic deoxygenation step followed by hydroprocessing. Similar to FT, HEFA consists of primarily iso-paraffins in the jet fuel carbon number range and exhibits similar properties, and may be blended up to $50 \%$ by volume with Jet A due to similar property limitations. Similar to FT-SPK, blending is required to add the normal paraffins, cycloparaffins, and aromatics that are absent from the HEFA.

\subsubsection{A3: Synthesized Iso-paraffıns From Hydroprocessed Fermented Sugars}

The alternative jet fuel blending component specified in this annex is a single hydrocarbon compound called farnesane (2,6,10Trimethyldodecane). An intermediate hydrocarbon product (an olefin) is produced from the fermentation of sugars using a genetically engineered microorganism. This is followed by hydroprocessing to produce the farnesane iso-paraffin final product. Petroleum-derived jet fuel consists of a range of hydrocarbons containing from 8 to 16 carbon atoms that supports stable combustion across the wide range of gas turbine engine operating conditions, but farnesane is a single hydrocarbon molecule containing 15 carbon atoms. To avoid overloading the blended jet fuel with hydrocarbons in one slice of the compositional distribution, SIP is limited to a $10 \%$ blend concentration.

\subsubsection{A4: Synthesized Kerosine With Aromatics Derived by Alkylation of Light Aromatics From Non-petroleum Sources}

This conversion process is an adaptation of the FT-SPK process specified in Annex A1 that produces a similar alternative jet fuel 
blend component, but with aromatics. It co-processes a benzenerich stream that is a by-product of coal gasification with the $\mathrm{C} 3$ and C4 olefins produced by the FT reactor during the downstream polymerization process step to produce alkylated aromatics along with isoparaffinic kerosene. The result is FT-SPK plus $15-20 \%$ aromatics and is called FT-SPK/A. The feed stocks, property limitations and blending limits are all similar to Annex A1. Because FT-SPK/A is compositionally identical to petroleumderived Jet A fuel, there are not any property limitations that necessitate blending of FT-SPK/A with conventional jet fuel. However, a maximum $50 \%$ blending limit was specified to allow the accumulation of service experience prior to permitting its use unblended.

\subsubsection{A5: Alcohol-To-Jet Synthetic Paraffinic Kerosene}

The conversion process described in this annex converts alcohol to an alternative jet fuel blending component. The process first dehydrates the alcohol to remove oxygen resulting in hydrocarbon olefins. Next, the olefins are oligomerized into higher molecular weight olefins (or unsaturated oligomers). The unsaturated oligomers that have molecular weights within the jet fuel range are separated and hydroprocessed to saturate the olefins into paraffins, resulting in the final ATJ-SPK jet fuel for blending purposes. ATJ-SPK is comprised primarily of isoparaffins and may currently be blended with conventional jet fuel at a $50 \%$ concentration to attain the other hydrocarbon molecular classes and to meet jet fuel property limits.

\subsubsection{A6: Synthesized Kerosene From Hydrothermal Conversion of Fatty Acid Esters and Fatty Acids}

The Annex A6 conversion process is called Catalytic Hydrothermolysis Jet $(\mathrm{CHJ})$. The $\mathrm{CHJ}$ process consists of hydrothermal conversion and hydrotreating of the same feed stock that HEFA uses resulting in a fully-formulated alternative jet fuel (including aromatics) with a similar distribution of hydrocarbon molecular classes and carbon number distribution. Because $\mathrm{CHJ}$ is compositionally identical to petroleum-derived Jet $\mathrm{A}$ fuel, there are not any property limitations that necessitate blending of $\mathrm{CHJ}$ with conventional jet fuel. However, a maximum $50 \%$ blending limit was specified to allow the accumulation of service experience prior to permitting its use unblended.

\subsubsection{A7: Synthesized Paraffinic Kerosene From Hydroprocessed Hydrocarbons, Esters and Fatty} Acids (HC-HEFA)

The process is the same as the Annex A2 HEFA conversion process and produces a mix of isoparaffins, normal paraffins, and cycloparaffins in the jet fuel carbon number range. However, this process specifies a different feed stock which is comprised of hydrocarbons in addition to free fatty acids and fatty acid esters. The Botryococcus braunii algae produces this feed stock, which is an oil containing a high percentage of unsaturated hydrocarbons known as botryococcenes, instead of triglycerides or fatty acids that other species of algae produce. This annex was the first to be approved under theD4054 Fast Track. As discussed earlier, the blend ratio of HC-HEFA with conventional jet fuel is limited to $10 \%$ maximum as required under the Fast Track process.

\section{REGULATORY BASIS FOR USE OF ASTM D7566 DROP-IN ALTERNATIVE JET FUELS}

Successful completion of the ASTM D4054 evaluation program that culminates in the issuance of an ASTM D7566 annex is aligned with the existing jet fuel approval basis for virtually all gas turbine powered aircraft operating around the globe. This in turn, enables use of D7566 fuels on these aircraft. This regulatory basis has been confirmed by the FAA and is documented in SAIB NE-11-56 (FAA Special Airworthiness Information Bulletin, 1956) and described below.

\subsection{Existing Jet Fuel Approval Basis}

Jet A or Jet A-1 fuel is the fuel specified for use on most turbine engine-powered aircraft currently in use or entering into service. Globally, many different specifications are used to define and control Jet A/A-1 fuel, but all are based on two primary specifications; ASTM D1655 or DEF STAN 91-091. As discussed earlier in this paper, this fuel definition is a regulatory requirement for each aircraft and engine manufacturer and any fuel that meets the Jet A/A-1 specification can be used on these aircraft.

\subsection{Jet A/A-1 Comparison}

As described previously, ASTM has issued standard practice D4054 that defines the testing required to compare the physical properties, chemical composition, and materials compatibility of candidate alternative jet fuels to typical petroleum-derived Jet A/A-1 fuels. If the test data indicates that the candidate alternative jet fuel is essentially identical to petroleum-derived jet fuel, then the ASTM subcommittee will take action to designate it as Jet A/A-1 fuel.

\subsection{Incorporation Into the Drop-In Fuel Specification}

If the candidate alternative jet fuel is concluded to be essentially identical to Jet A/A-1, the ASTM subcommittee will approve a ballot to add it to ASTM D7566, the drop-in jet fuel specification, as a new annex. The annex will include all of the necessary information to describe and control the new alternative fuel, such as descriptive criteria for the feed stock, conversion process, and composition, along with prescriptive criteria for the physical properties and composition. As described in the previous section, all of the fuels defined in the D7566 annexes currently specify a maximum blending percentage for blending with conventional jet fuel. D7566 is structured to require two testing steps when producing the annex fuel. First, each batch of alternative fuel must be tested to the annex criteria. In the second step, testing of the finished jet fuel after blending with the annex fuel to the criteria in the main body of the specification is required.

\subsection{Re-Designation as ASTM D1655 Jet A/A-1 Fuel}

Both ASTM D7566 and ASTM D1655 include language that allows the re-designation of D7566 fuel as D1655 Jet A/A-1 fuel. 
This is deemed acceptable because the criteria in D7566 is more stringent than the criteria in D1655, and therefore every batch of D7566 fuel will comply with the D1655 specification requirements.

As a result of the re-designation, the alternative jet fuel is now considered a Jet A/A-1 fuel and therefore meets the certificated aviation fuel operating limitations of virtually all turbine enginepowered aircraft. It now meets the existing certification basis and can be used without any limitations, restrictions, or special handling provisions, effectively meeting the existing approval basis described above. The new fuel can seamlessly enter the jet fuel supply chain without any additional approvals. In summary, the approval to fly with a particular alternative jet fuel annex in D7566 is granted via issuance of that annex in D7566.

\section{CONCLUSION}

The aviation fuel community has established a collaborative approach to evaluating and approving alternative jet fuels that

\section{REFERENCES}

ASTM (2018). “ASTM D4054 Clearinghouse Guide https://s3.wp.wsu.edu/ uploads/sites/192/2018/03/clearinhouse.pdf.

ASTM International Standard D1655 (1942). "Standard Specification for Aviation Turbine Fuels.", ASTM International, West Conshohocken, PA, USA: -2959.

ASTM International Standard D7566 (1942). Standard Specification for Aviation Turbine Fuel Containing Synthesized Hydrocarbons", ASTM International, West Conshohocken, PA, USA .

ASTM International Standard D4054 (1942). "Standard Practice for Qualification and Approval of New Aviation Turbine Fuels and Fuel Additives", ASTM International, West Conshohocken, PA, USA .

CAAFI Prescreening Guidance for Alternative Jet Fuels”. Available:https://caafi. org/tools/Prescreening_Guidance.html.

Colket, M. B., Heyne, J. S., Rumizen, M., Edwards, J. T., Gupta, M., Roquemore, W. M., et al. (2017). An Overview of the National Jet Fuels Combustion Program. Reston, VA: AIAA Journal 55.

Defence Standard 91-091 Turbine Fuel, Aviation Kerosine Type, Jet A-1 NATO Code: F-35, Joint Service Designation: AVTUR", Issued by the United Kingdom (U.K.) Ministry of Defence. Glasglow, UK, https://www.dstan.mod.uk/.

FAA Special Airworthiness Information Bulletin. (1956). NE-11-56, "Engine Fuel and Control - Semi-Synthetic Jet Fuel", FFA Aviation Safety, Washington, DC, USA, https://www.faa.gov/aircraft/safety/.

Heyne, J., "Fuel Effects on Operability of Aircraft Gas Turbine Combustors", AIAA, Reston, VA, USA, (2021). utilizes the expertise of key stakeholders via the ASTM International consensus-based specification process. The alternative jet fuels that result from this process have essentially identical properties and composition which enables seamless entrance into the existing, well-established jet fuel supply infrastructure without any special handling or accommodations. Additional approvals from the national aviation authorities are not required and these fuels can be used on virtually all existing gas-turbine powered aircraft without any modifications. This process, developed by CAAFI and the FAA, lowers one of the many barriers to entry of sustainable aviation fuels into the aviation fuel supply chain and therefore contributes to reducing aviation's carbon emissions.

\section{AUTHOR CONTRIBUTIONS}

The author confirms being the sole contributor of this work and has approved it for publication.

Mil-Dtl-5624 (1873). Detail Specification, Turbine Fuel, Aviation, Grades JP-4 and $J P-5$. Lakehurst, NJ: Naval Air Warfare Center, Aircraft Division. https://assist. dla.mil.

Mil-Dtl-83133 (2430). Detail Specification, Turbine Fuel, Aviation, Kerosene Type, AFPET/PTPS, Dayton, OH, USA. https://assist.dla.mil.

Mil-Hdbk-510A, (2017). Aerospace Fuels Certification, AFLCMC/EN-EZ, Dayton, OH, USA. Standards@us.af.mil https://assist.dla.mil.

Rauch, B. "Jetscreen" Available:

Conflict of Interest: The author declares that the research was conducted in the absence of any commercial or financial relationships that could be construed as a potential conflict of interest.

Publisher's Note: All claims expressed in this article are solely those of the authors and do not necessarily represent those of their affiliated organizations, or those of the publisher, the editors and the reviewers. Any product that may be evaluated in this article, or claim that may be made by its manufacturer, is not guaranteed or endorsed by the publisher.

Copyright (c) 2021 Rumizen. This is an open-access article distributed under the terms of the Creative Commons Attribution License (CC BY). The use, distribution or reproduction in other forums is permitted, provided the original author(s) and the copyright owner(s) are credited and that the original publication in this journal is cited, in accordance with accepted academic practice. No use, distribution or reproduction is permitted which does not comply with these terms. 